\title{
Expression of c-fos Protein in Rat Brain Elicited by Electrical Stimulation of the Pontine Parabrachial Nucleus
}

\author{
Teresa L. Krukoff, ${ }^{1}$ Tracy L. Morton, ${ }^{1}$ Kim H. Harris, ${ }^{2}$ and Jack H. Jhamandas ${ }^{2}$ \\ Departments of 'Anatomy and Cell Biology, and 'Medicine, Division of Neuroscience, Faculty of Medicine, University of \\ Alberta, Edmonton, Canada T6G 2H7
}

The expression of Fos, the protein product of the primary response gene c-fos, was used metabolically to map the short-term ( $1 \mathrm{hr}$ ) effects of urethane and sodium pentobarbital anesthesia in rat. Subsequently, urethane-anesthetized rats were used to study the integrated response to electrical stimulation (1-1.5 hr) of the pontine parabrachial nucleus (PBN), an important center for relay of autonomic information in the brain. Immunohistochemistry was used to localize Foslike immunoreactivity (FLI) in the brain.

To approximate amounts of $\mathrm{FLI}$ in the conscious animal, rats were killed immediately after attaining surgical anesthesia with sodium pentobarbital $(50 \mathrm{mg} / \mathrm{kg})$ or urethane (1.2$1.7 \mathrm{gm} / \mathrm{kg}$ ). No FLI was found in the brains of these rats. In rats killed $1 \mathrm{hr}$ after anesthesia with sodium pentobarbital, FLI was found only in the habenulae. After $1 \mathrm{hr}$ of urethane anesthesia, low levels of FLI were found in the following areas: nucleus of the tractus solitarius (NTS); caudal and rostral ventrolateral medulla (VLM); lateral PBN; ventromedial, paraventricular, and supraoptic nuclei (SON) of the hypothalamus; medial preoptic area; central nucleus of the amygdala (ACE); endopiriform cortex; insular cortex; piriform cortex; and islands of Calleja.

Electrical stimulation of the PBN (10 sec on, $10 \mathrm{sec}$ off; 15-50 $\mu \mathrm{A}$ at $20 \mathrm{~Hz}$ for $60-90 \mathrm{~min}$ ) in rats anesthetized with urethane led to increases in mean arterial pressure (10-30 $\mathrm{mm} \mathrm{Hg}$ ) and to ipsilateral increases of FLI in the lateral PBN, dorsal division of SON, ACE, endopiriform nucleus, insular cortex, piriform cortex, and islands of Calleja. In two animals, ipsilateral increases were found in the ventromedial hypothalamus and medial amygdaloid nucleus. Finally, consistent bilateral increases in FLI were found in the NTS, caudal and rostral VLM, and area postrema.

These data confirm that sodium pentobarbital has a generally depressive effect on neural activity. Expression of Fos within autonomic centers in rats anesthetized with urethane for $1 \mathrm{hr}$ may be due to the consistent drop in arterial pressure that occurs during anesthesia. Ipsilateral increases of FLI in discrete brain regions of rats in which the PBN was stimulated indicate that alterations are likely due to the electrical

\footnotetext{
Received Dec. 23, 1991; revised Apr. 8, 1992; accepted Apr. 15, 1992.

We thank Greg Morrison for photographic assistance. This work was supported by the Medical Research Council of Canada and Alberta Heritage Foundation for Medical Research.

Correspondence should be addressed to Dr. Teresa L. Krukoff, Department of Anatomy and Cell Biology, Faculty of Medicine, University of Alberta, Edmonton, Alberta, Canada T6G 2H7.

Copyright (C) 1992 Society for Neuroscience $0270-6474 / 92 / 123582-09 \$ 05.00 / 0$
}

stimulation whereas bilateral increases (in NTS and VLM) are likely due to the increases in arterial pressure that accompany PBN stimulation.

$C$-fos, one of a small group of genes called primary response gcnes (reviewed by Herschman, 1989), and its protein product, Fos, are integral components of complex signaling mechanisms believed to be responsible for the cell's response to stimulation (Curran, 1988). Therefore, the expression of this gene is being increasingly used as a means to identify functionally neurons that are part of specific pathways in the CNS. The effects of many types of stimulation including drug-induced seizures, activation of receptors, growth factors, neuroactive drugs, electrical stimulation, and physiological states have now been studied with this method (Curran, 1988; Sagar et al., 1988; Ceccatelli et al., 1989; Morgan and Curran, 1989, 1991; Doucet et al., 1990; Popovici et al., 1990; Sheng and Greenberg, 1990; Anton et al., 1991; Jones and Evinger, 1991).

The parabrachial nucleus of the pons $(\mathrm{PBN})$ is a major relay center for the transfer of autonomic, including cardiovascular, information throughout the brain. While neuroanatomical and electrophysiological techniques have been used successfully to determine the connections of the PBN with areas of the brainstem and forebrain (Norgren and Leonard, 1973; Saper and Loewy, 1980; King and Knox, 1982; Block and Schwartzbaum, 1983; Cechetto and Calaresu, 1983; van der Kooy and Koda, 1983; Fulwiler and Saper, 1984; Holstege, 1988; Schwaber et al., 1988; Granata and Kitai, 1989; Moga et al., 1989; Berkley and Scofield, 1990; Herbert et al., 1990; Papas and Ferguson, 1990; Touzani et al., 1990; Wild et al., 1990; Bernard et al., 1991; Jhamandas et al., 1991; Krukoff et al., 1992), less is known about the integrated response of these areas to activation of efferent projections originating in the PBN. Therefore, using Fos-like immunoreactivity (FLI) as a marker of cell stimulation, it was our goal to determine the effect of electrical stimulation in the PBN on other regions in the CNS.

The anesthetic urethane was chosen for these experiments because sympathetic and parasympathetic reflexes are preserved under anesthesia (Maggi and Meli, 1986a,b), in contrast to the depressant effects of other anesthetics such as barbiturates (Baum et al., 1985; Morgan et al., 1987). However, the effects of urethane anesthesia on FLI in an otherwise unstimulated brain have not been well defined. Therefore, before studying the effects of PBN electrical stimulation on FLI, we investigated the effects of urethane anesthesia on FLI in the brain immediately after and $\mathrm{l} \mathrm{hr}$ after rats had attained levels of surgical anesthesia, and compared these results with those from animals anesthetized with sodium pentobarbital. 


\section{Materials and Methods}

Male Sprague-Dawley rats were purchased from the University of Alberta Biological Sciences Animal Center. They were housed, two to a cage, in a $12 \mathrm{hr}: 12 \mathrm{hr}$ light/dark cycle (lights on at 0800 ) at $20^{\circ} \mathrm{C}$ and given free access to rat chow and water.

Effects of anesthetic. Animals were divided into four groups of eight rats each. Rats in group 1 received intraperitoneal injections of sodium pentobarbital $(50 \mathrm{mg} / \mathrm{kg}$; Somnotol, M.T.C. Pharmaceuticals, Hamilton, Canada) and were killed immediately after levels of surgical anesthesia were attained (approximately $5 \mathrm{~min}$ ). Rats in group 2 received intraperitoneal injections of urethane $(1.2-1.7 \mathrm{gm} / \mathrm{kg}$; Sigma Chemicals, St. Louis, MO) and were also killed immediately after attaining levels of surgical anesthesia (approximately $8 \mathrm{~min}$ ). These two groups served as controls to determine comparable levels of Fos expression in conscious animals since it has been shown that the short time between administration of anesthetic and death is not sufficient to allow measurable changes in Fos levels within the brain, as determined with immunohistochemistry (Dragunow and Faull, 1989). Rats in groups 3 and 4 received intraperitoneal injections of sodium pentobarbital and urethane, respectively, and were killed $1 \mathrm{hr}$ after levels of surgical anesthesia were attained. Tissues from rats of different groups were processed in pairs to ensure that comparisons could be made among animals from all groups.

Electrical stimulation of PBN. In urethane-anesthetized rats $(n=6)$, the femoral artery was catheterized to permit continuous monitoring of arterial blood pressure. Body temperature was maintained at $37^{\circ} \mathrm{C}$ using a thermistor-controlled feedback heating blanket. Rats were positioned in a stereotaxic device, and a 30 gauge concentric bipolar stimulating electrode (tip-ring separation, $<0.25 \mathrm{~mm}$; impedance, $400-600 \mathrm{k} \Omega$ ) was placed in the PBN. The optimal site for electrode placement in the PBN was determined by evoking a maximal pressor response following a brief high-frequency train of cathodal pulses $(1 \mathrm{sec}, 50 \mathrm{~Hz}$; Jhamandas et al., 1991). The PBN was then stimulated every $10 \mathrm{sec}$ with a $10 \mathrm{sec}$ train of rectangular pulses (pulse duration, $100 \mu \mathrm{sec}$ ) at a frequency of $20 \mathrm{~Hz}$ and current intensities of $15-50 \mu \mathrm{A}$ for $60-90 \mathrm{~min}$. Increases in mean arterial pressures (MAP) of $15-25 \mathrm{~mm} \mathrm{Hg}$ (Fig. 10) during each train of pulses were taken as evidence that PBN efferents were being activated.

Control animals ( $n=2$ in each group) were treated in one of the following ways: (1) the rat was anesthetized with no further manipulation, (2) sites outside of the PBN were stimulated (e.g., cerebellum) using the same stimulus parameters, or (3) the electrode was placed in the PBN but no current was passed.

Placements of electrodes were histologically verified at the end of each experiment. Tissues from pairs of rats (stimulation of PBN plus one of the controls) were processed together.

Processing of tissues. Anesthetized rats were perfused transcardially with $100 \mathrm{ml}$ of saline followed by ice-cold $4 \%$ paraformaldehyde (Sigma) in $0.1 \mathrm{M}$ phosphate buffer, $\mathrm{pH} 7.2$. Brains were removed and cryoprotected by successively placing them into solutions of $10 \%, 20 \%$, and $30 \%$ sucrose (in water) for approximately $12 \mathrm{hr}$ each. Serial transverse sections of the brains $(50 \mu \mathrm{m})$ were cut in a cryostat $\left(-18^{\circ} \mathrm{C}\right)$ and collected in phosphate-buffered saline (PBS, $\mathrm{pH}$ 7.2).

FLI was demonstrated immunohistochemically by placing tissue sections into sheep antiserum against Fos (Cambridge Research Biochemicals, Valley Stream, NY) diluted 1:2000 in 0.3\% Triton X-100/PBS containing normal rabbit serum diluted 1:100. According to the supplier's specifications, this affinity-purified polyclonal antibody recognizes Fos and Fos-related proteins. Therefore, the staining we have obtained will be described as Fos-like immunoreactivity (FLI).

Tissues were processed the next day using the avidin-biotin immunoperoxidase method (ABC VectaStain Kit, Vector Labs, Burlingame, $\mathrm{CA}$ ), and FLI was visualized as a brown reaction product with the chromagen diaminobenzidine (Sigma). Sections were rinsed in PBS and mounted onto glass microscope slides, air dried, and coverslipped. Tissues were analyzed and photographed using a Zeiss light microscope.

\section{Results}

\section{Effects of anesthesia}

No FLI was found in brains of rats killed immediately after anesthesia. In rats processed $1 \mathrm{hr}$ after initiation of anesthesia with sodium pentobarbital, FLI was found only in the habenular nuclei (Fig. 1).

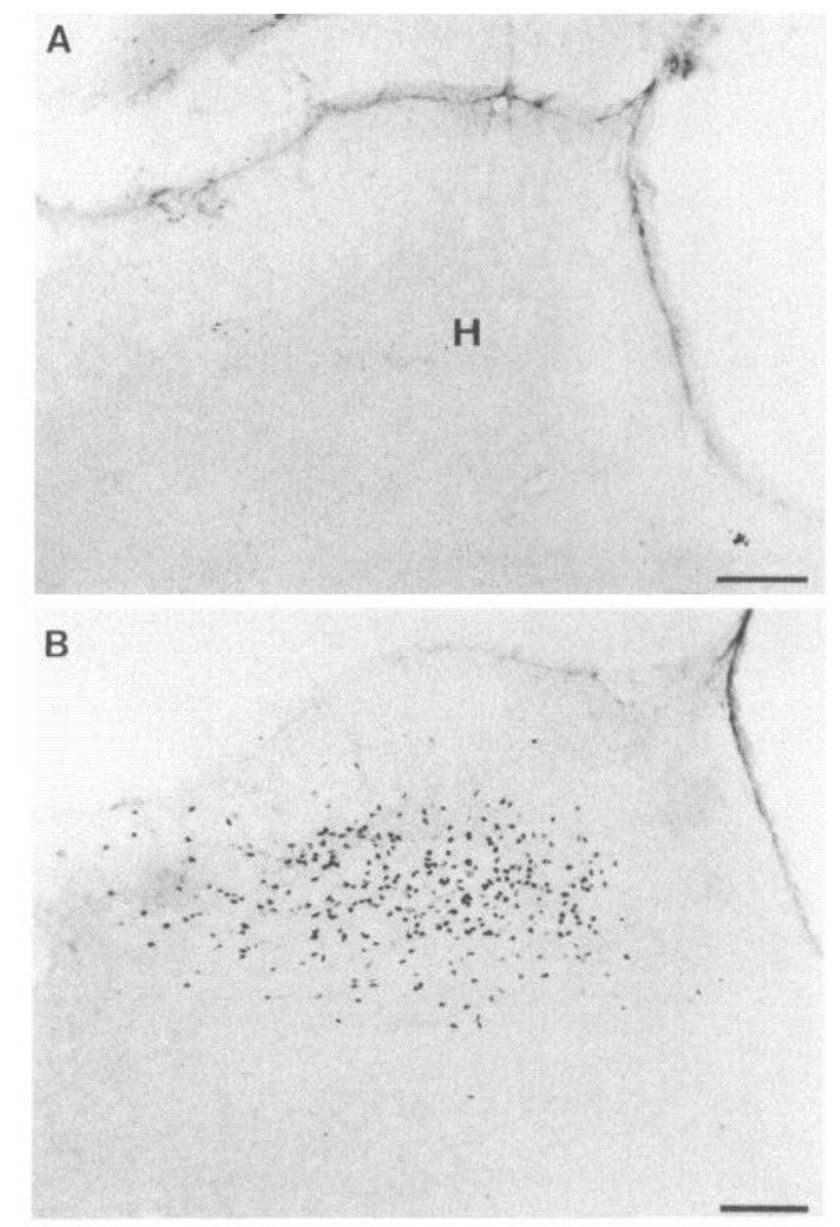

Figure 1 Effect of sodium pentobarbital anesthesia on FLI in habenula $(H)$ shown by comparing lack of FLI in habenulae from brains of rats killed immediately after attaining surgical anesthesia $(A)$ with FLI in habenulae from brains of rats killed $1 \mathrm{hr}$ after attaining anesthesia $(B)$. Scale bars, $100 \mu \mathrm{m}$.

In rats processed $1 \mathrm{hr}$ after initiation of anesthesia with urethane, low levels of FLI were found bilaterally in the following areas: nucleus of the tractus solitarius (NTS) rostral to the area postrema (AP; Fig. 2C), caudal and rostral ventrolateral medulla (VLM; Fig. 2E), lateral PBN (Fig. 3A), ventromedial hypothalamus (VMH; Fig. 4A), paraventricular nucleus of the hypothalamus (PVN; Fig. 5), supraoptic nucleus of the hypothalamus (SON; Fig. 6A), medial preoptic area, central nucleus of the amygdala (ACE; Fig. 7A), endopiriform cortex (Fig. 4C), insular cortex (Fig. $8 A$ ), piriform cortex (Fig. $8 C$ ), and islands of Calleja (Fig. 9A). In the PVN, most neurons with FLI were located in the parvocellular division (Fig. 5). In the SON, most neurons with FLI were located in the ventral division of the nucleus (Fig. 6A).

\section{PBN stimulation}

In urethane-anesthetized control and experimental rats prior to electrical stimulation, MAP consistently decreased from normal resting levels by $10-30 \mathrm{~mm} \mathrm{Hg}$ (Fig. 10). Controls animals showed no further changes in blood pressure.

During the period of stimulation, MAP rose by $18 \pm 2 \mathrm{~mm}$ $\mathrm{Hg}(x \pm \mathrm{SE})$. Pulses of current caused additional increases of 

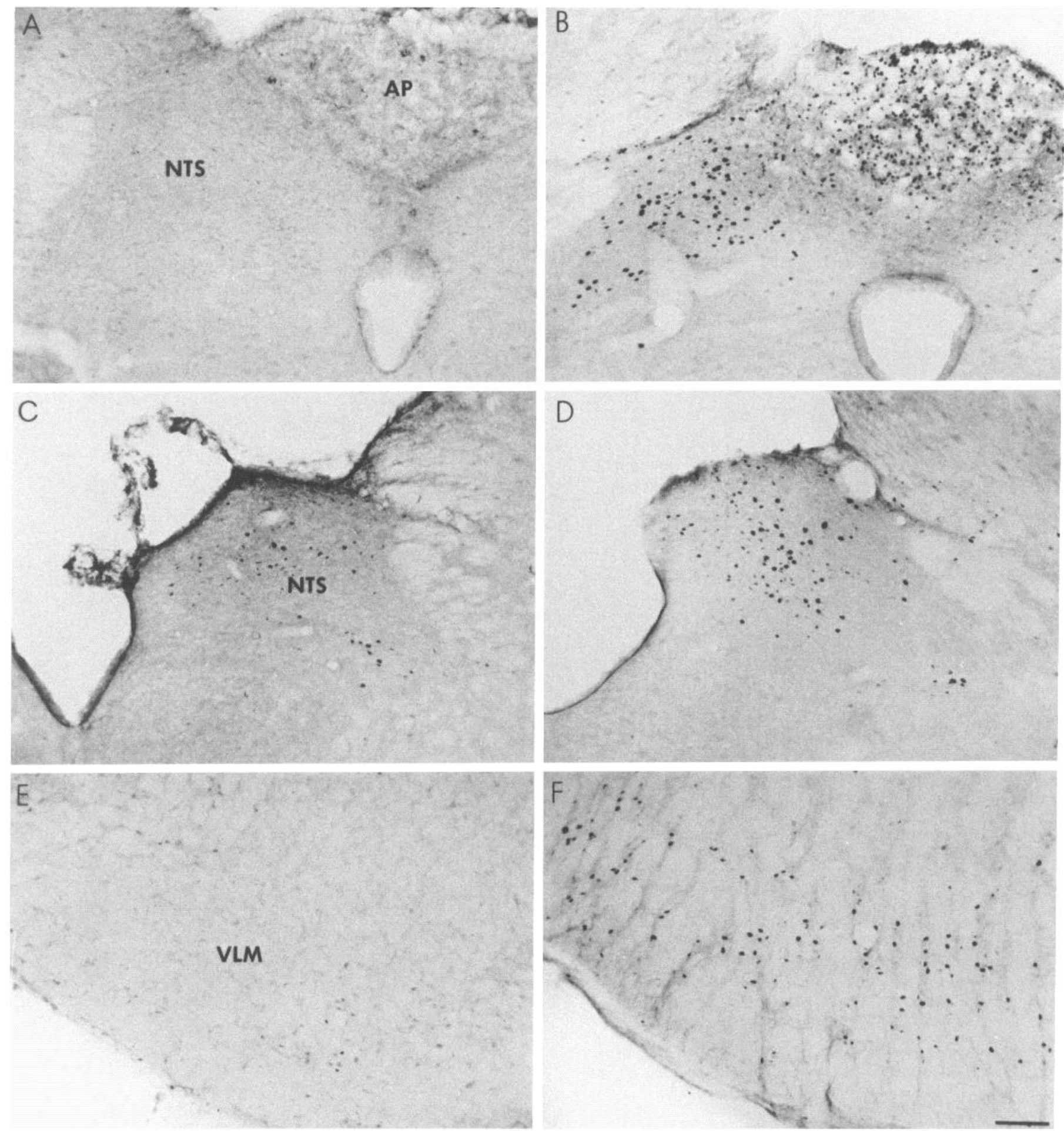

Figure 2. FLI in NTS and AP, the NTS just rostral to the AP, and caudal VLM in rats anesthetized with urethane for $1 \mathrm{hr}(A, C$, and $E)$ and in urethane-anesthetized rats in which the PBN was electrically stimulated $(B, D$, and $F)$. In stimulated rats, bilateral increases in FLI were observed in the NTS, AP, and VLM. Scale bar, $100 \mu \mathrm{m}$ (for $A-F$ ).

$12 \pm 1 \mathrm{~mm} \mathrm{Hg}(x \pm \mathrm{SE})$ (Fig. 10). In all animals, the electrode tip was located in the lateral division of the PBN (Fig. 3).

FLI in tissues from rats controlled for stimulation (see Electrical stimulation of PBN, above) was similar to that seen in rats from group 4 (described above). In electrically stimulated rats, increases in FLI were found in the stimulated PBN (Fig.
$3 B, C$ ). Consistent ipsilateral increases in FLI were also found in the following areas (Figs. 4, 6-9): dorsal division of SON, ACE, endopiriform cortex, insular cortex, piriform cortex, and islands of Calleja. In two animals, ipsilateral increases were found in the VMH (Fig. 4B) and medial amygdaloid nucleus (Fig. $7 D$ ). Finally, consistently increased bilateral staining in- 
tensities were found in the NTS (at the level of and rostral to the AP; Fig. $2 B, D$ ), caudal and rostral VLM (Fig. $2 F$ ), and the AP (Fig. 2B).

\section{Discussion}

This study contributes two major new findings. First, urethane anesthesia leads to low levels of FLI in autonomic centers of the brain, many of which have been implicated for their roles in regulation of autonomic function. Second, electrical stimulation of the pontine PBN causes ipsi- and bilateral increases of FLI in a number of brain sites that have been previously identified to be direct or indirect targets of projections originating in the PBN.

\section{FLI immediately after anesthesia induction}

We have used levels of FLI immediately following attainment of surgical levels of anesthesia ( $8 \mathrm{~min}$ or less) as an approximation of Fos activity in the conscious animal since it has been shown that approximately $15 \mathrm{~min}$ of stimulation are required before changes in FLI can be observed (Dragunow and Faull, 1989). Our results show no FLI in brains of these rats.

\section{Anesthetic-dependent FLI}

Urethane. Urethane is regarded as the anesthetic of choice in studies of the cardiovascular system because it preserves cardiovascular reflexes where both sympathetic and parasympathetic divisions of the autonomic nervous system are active (Maggi and Meli, 1986a,b) and does not interfere with respiratory function (Sapru and Krieger, 1979). Our results show that urethane anesthesia of $1 \mathrm{hr}$ in duration leads to low levels of FLI within the NTS, VLM, and lateral PBN of the brainstem, and the VMH, parvocellular PVN, SON (ventral division), medial preoptic area, ACE, endopiriform cortex, insular cortex, piriform cortex, and islands of Calleja. Many of these regions have been strongly implicated in mediating autonomic and especially cardiovascular responses. In view of the consistent drop in MAP of urethane-anesthetized rats observed in this study and in others (Maggi and Meli, 1986a), it is possible that these areas may be reflexively stimulated in response to the anesthetic-evoked hypotension. For example, the VLM, which exhibits low levels of FLI, is generally composed of rostral and caudal subdivisions where the rostral VLM is thought to be the site of neurons that generate vasomotor tone while the caudal VLM regulates the activity of the rostral VLM (Calaresu and Yardley, 1988). In support of the idea of reflex activation are findings of increased sympathetic outflow to the periphery in urethane-anesthetized rats (Reinert, 1964; Armstrong et al., 1982). A direct depressant action on vascular smooth muscle contractility likely underlies the hypotension observed in urethane-anesthetized rats (Maggi and Meli, 1986a).

Sodium pentobarbital. Sodium pentobarbital is a well-known depressant of brain activity (Baum et al., 1985; Morgan et al., 1987), and our results confirm its effect. Like urethane, sodium pentobarbital causes decreases in levels of blood pressure (Feldberg and Guertzenstein, 1972; Baum et al., 1985), but unlike the results for urethane discussed above, no increases in FLI were observed in regions of the brain that we might expect to be activated by the hypotension. These differences in results may be due, in part, to the depressant influence of sodium pentobarbital on the activity of most central neurons via GABAergic mechanisms (Nicholl, 1979; Richter and Holman, 1982). In rats anesthetized for $1 \mathrm{hr}$, only the habenula showed consis-
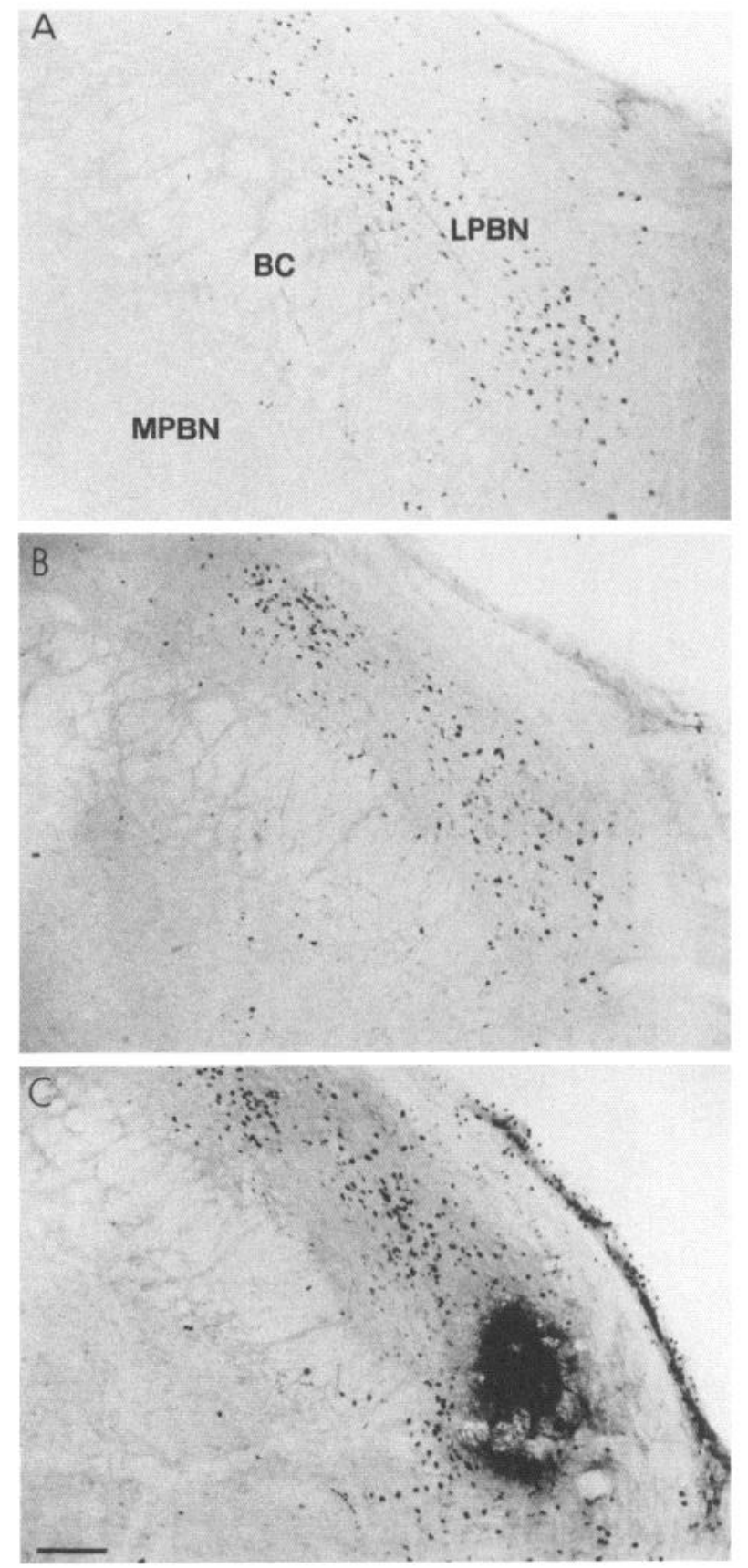

Figure 3. FLI in lateral $\mathrm{PBN}(L P B N)$ in rats anesthetized with urethane for $1 \mathrm{hr}(A)$ and in urethane-anesthetized rats in which the ipsilateral PBN was stimulated at a different level $(B)$. An example of a stimulation site is shown in $C$. $M P B N$, medial $\mathrm{PBN} ; B C$, brachium conjunctivum. Scale bar, $100 \mu \mathrm{m}$ (for $A-C$ ).

tent increases in FLI compared to control rats; the significance of increased activity in this region is not known at this time.

\section{Electrical stimulation of PBN}

Increases in levels of arterial blood pressure were used in this study as indices by which to verify accurate placement of electrodes in the PBN and activation of pathways relaying cardiovascular activity. The use of electrical stimulation does not allow us to determine whether neuronal perikarya, axons of passage, or both were stimulated. Nevertheless, the placement of the electrode into the lateral division of the PBN, a region known 

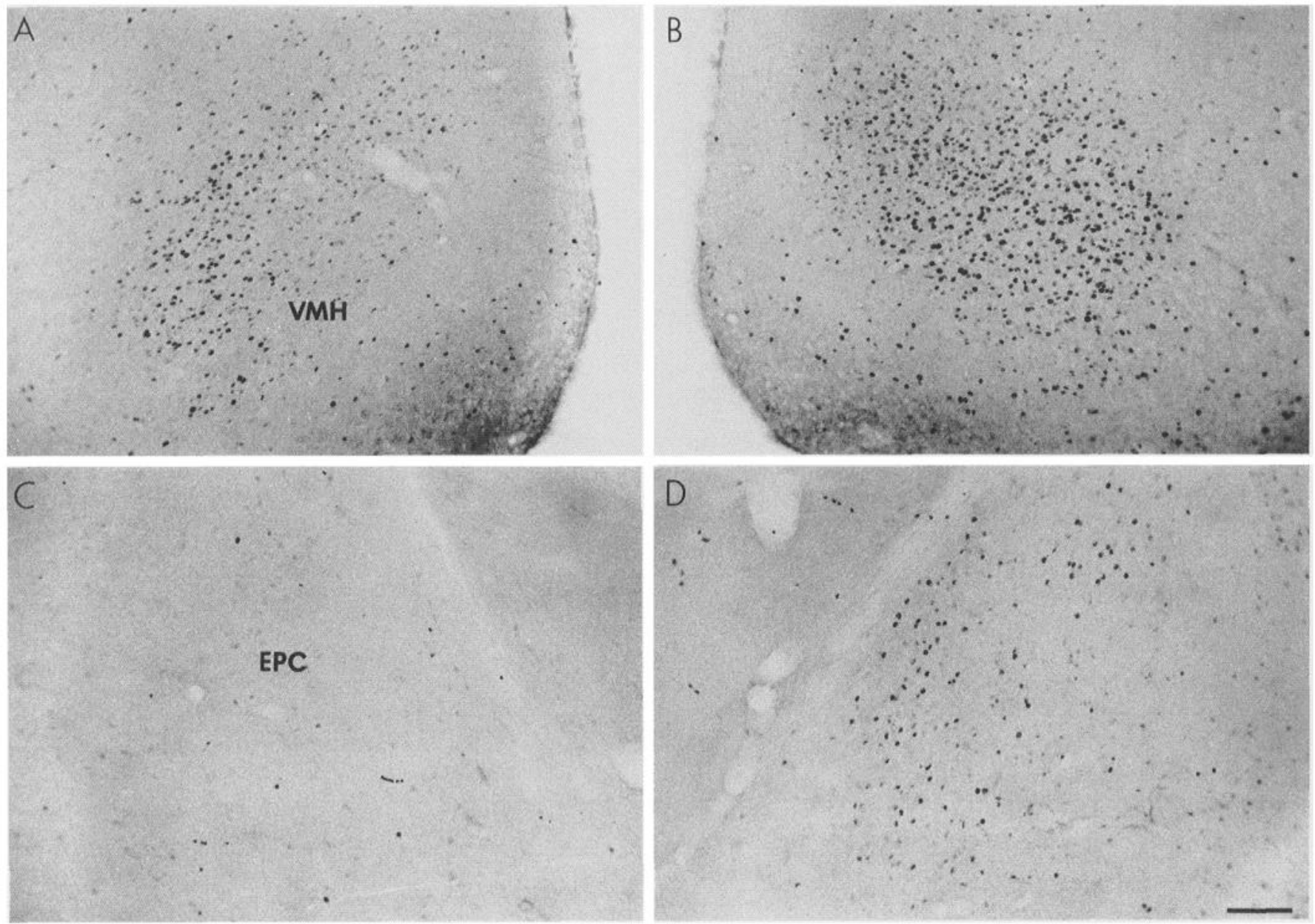

Figure 4. FLI in VMH $(A$ and $B)$ and endopiriform nucleus $(E P C ; C$ and $D)$ in urethane-anesthetized rats in which the PBN was stimulated on one side. Immunostaining in the nuclei contralateral to stimulation ( $A$ and $C$ ) was similar to that seen in rats anesthetized only. Nuclei ipsilateral to stimulation showed increases in FLI ( $B$ and $D$ ). Scale bar, $100 \mu \mathrm{m}$ (for $A-D$ ).

Figure 5. FLI in PVN in urethaneanesthetized rats in which the PBN was stimulated on one side. No differences in immunostaining were found between the contralateral PVN $(A)$ and ipsilateral PVN $(B)$. Scale bars, $100 \mu \mathrm{m}$.
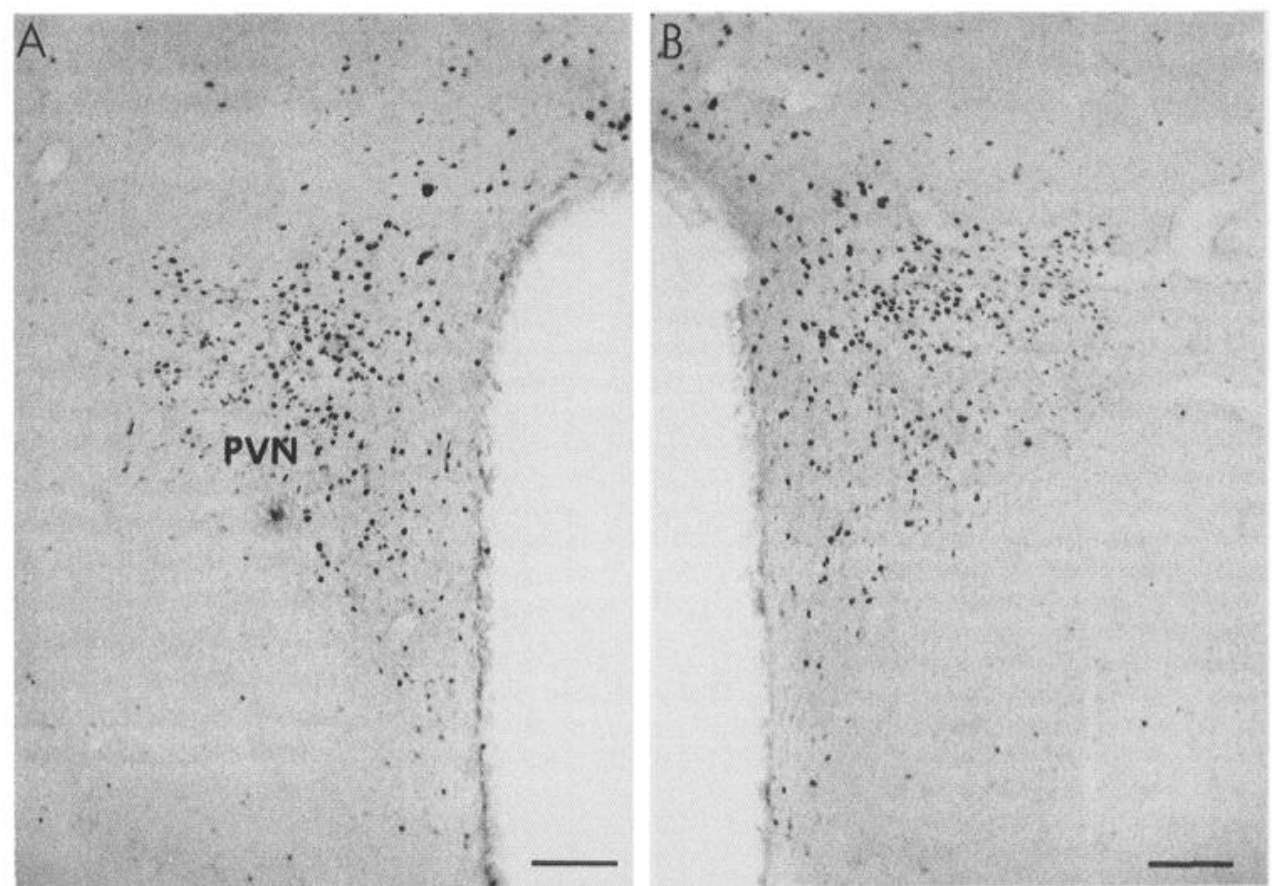

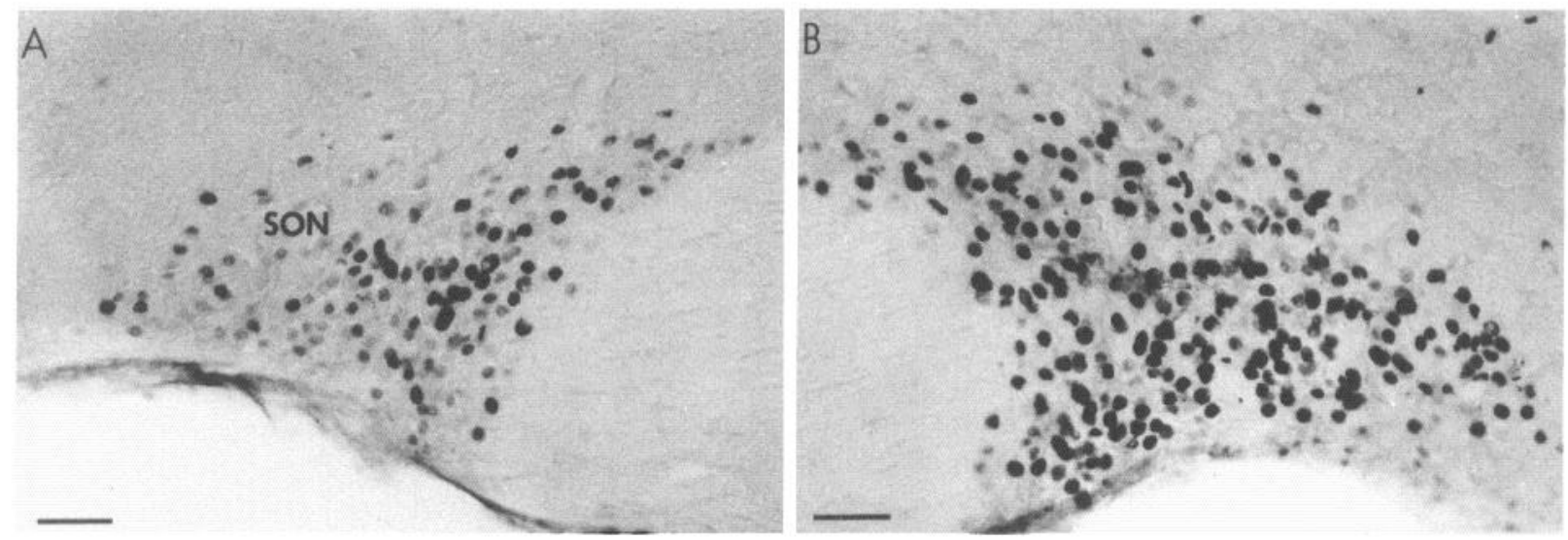

Figure 6. FLI in SON in urethane-anesthetized rats in which the PBN was stimulated on one side. Immunostaining in the SON ipsilateral to the stimulated PBN $(B)$ showed increases in Fos-positive cells throughout the nucleus and especially in the dorsal subdivision of SON compared to the SON contralateral to stimulation $(A)$. Scale bars, $60 \mu \mathrm{m}$.

to be a recipient of cardiovascular-related information (Cechetto and Calaresu, 1983; Ward, 1988), and the low levels of current necessary to elicit an increase in arterial pressure suggest that stimulation is reasonably well confined to the PBN. Moreover, the cardiovascular responses elicited in this study are similar to those obtained after chemical stimulation of cell bodies in PBN with microinjections of glutamate (Ward, 1988).

Ipsilateral induction of FLI. The unilateral nature of many of
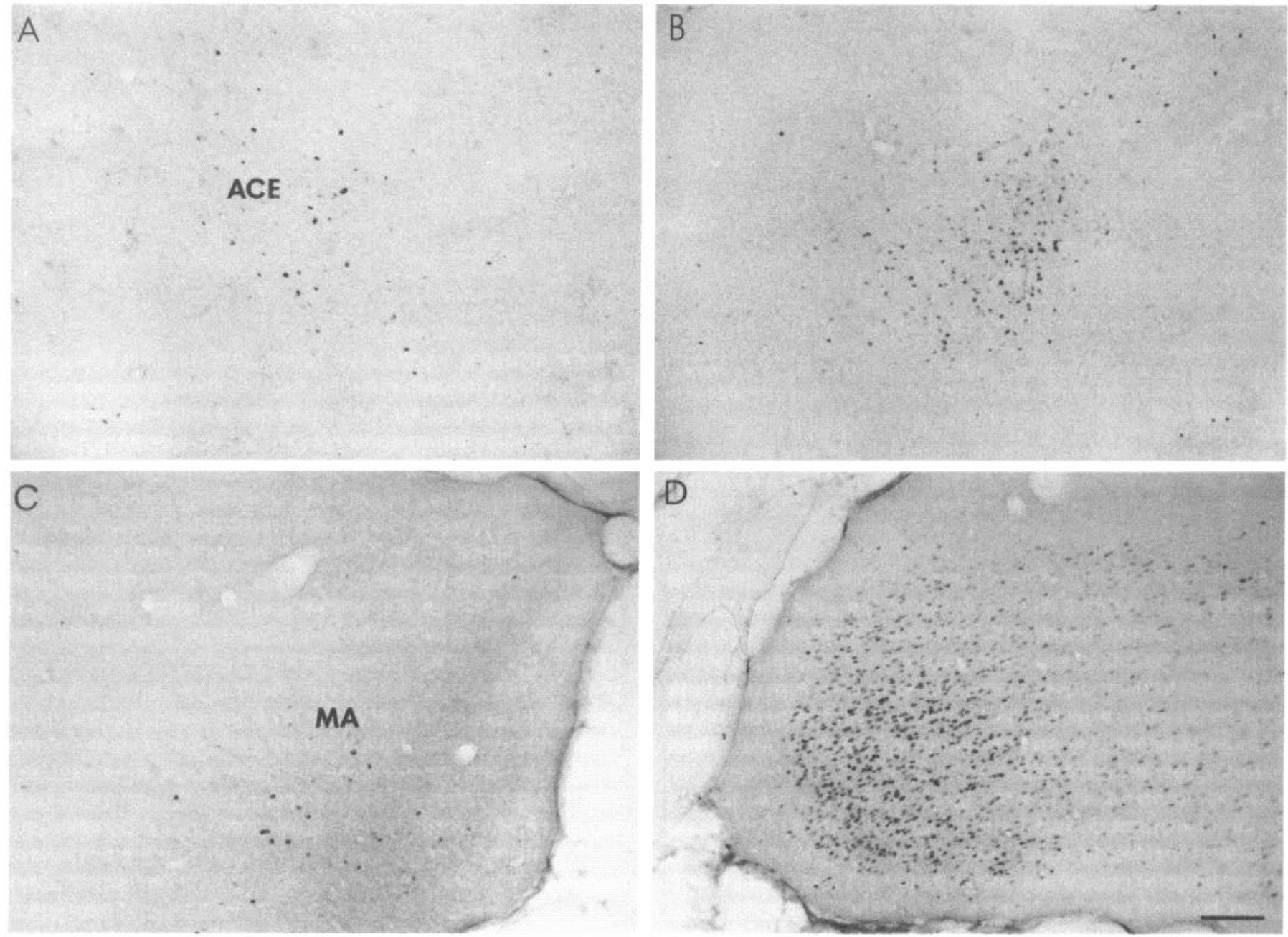

Figure 7. FLI in ACE $(A$ and $B)$ and medial amygdaloid nucleus $(M A ; C$ and $D)$ in urethane-anesthetized rats in which the PBN was stimulated on one side. Immunostaining in the nuclei contralateral to stimulation $(A$ and $C)$ was similar to that seen in rats anesthetized only. Nuclei ipsilateral to stimulation showed increases in FLI $(B$ and $D$ ). Scale bar, $100 \mu \mathrm{m}$ (for $A-D)$. 

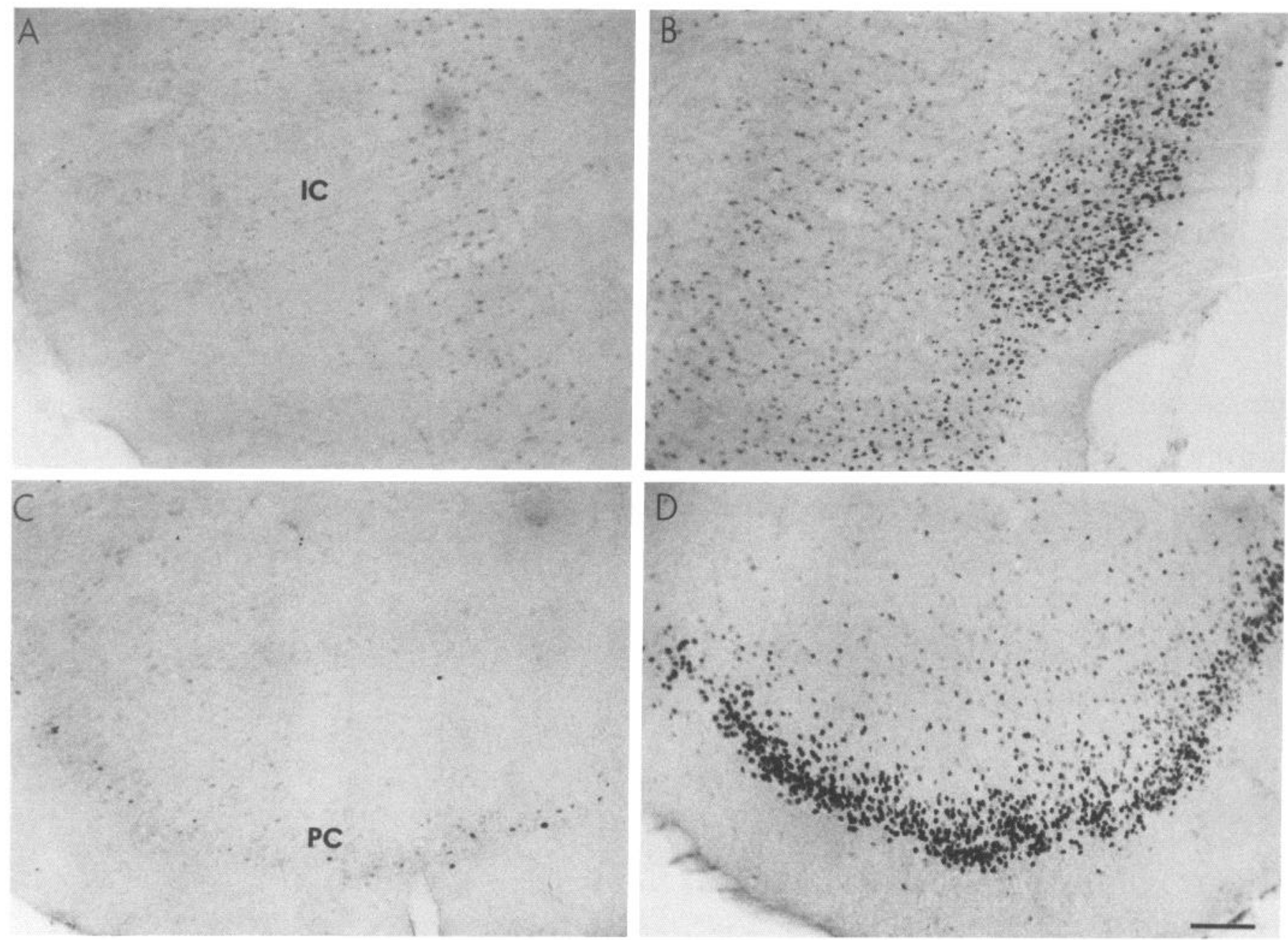

Figure 8. FLI in insular cortex $(I C: A$ and $B)$ and piriform cortex $(P C ; C$ and $D)$ in urethane-anesthetized rats in which the PBN was stimulated on one side. Immunostaining in the nuclei contralateral to stimulation $(A$ and $C)$ was similar to that seen in rats anesthetized only. Nuclei ipsilateral to stimulation showed increases in FLI $(B$ and $D$ ). Scale bar, $100 \mu \mathrm{m}$ (for $A-D$ ).

the increases in FLI resulting from this stimulation strongly suggests that these alterations were due to electrical stimulation and not to changes in levels of arterial pressure. Of the areas showing increased FLI, the insular cortex (Saper, 1982; Cechetto and Saper, 1987) and ACE (Block and Schwartzbaum, 1983; Schwaber et al., 1988; Block et al., 1989) receive robust direct projections from the PBN. Although the PBN does not have a significant direct projection to the SON, this nucleus may be activated via an interneuronal network located in the perinuclear zone dorsal to the SON (Jhamandas et al., 1991). Finally, although our results strongly suggest that the changes we have observed are due to orthodromic activation of neurons found in the PBN, we cannot entirely rule out the possibility that FLI at more rostral sites may be due to activation of collateral branching inputs to the $\mathrm{PBN}$ that originate in more caudal regions of the brainstem.

Our results support the notion that multisynaptic pathways can be demonstrated on the basis of FLI due to stimulation (Menetrey et al., 1989). The pronounced increase in FLI within the piriform cortex is likely due to stimulation of a multisynaptic pathway as the PBN does not project directly to this structure (Fulwiler and Saper, 1984). Stimulation of FLI in the piriform cortex with epileptic seizures induced with amygdala kindling (Dragunow et al., 1988) suggests that this multisynaptic pathway may involve the amygdala.

Bilateral induction of FLI. The bilateral nature of increases in FLI found in the NTS, VLM, and AP of the medulla suggests that these areas are being stimulated as a result of the increases in arterial pressure that accompany PBN stimulation. These results are not surprising in view of the roles of these structures in cardiovascular regulation (Calaresu et al., 1984).

The PBN has reciprocal connections with the NTS and VLM (Ross et al., 1981; Fulwiler and Saper, 1984; Herbert et al., 1990; Krukoff et al., 1992), so electrical stimulation of the PBN may also have an effect on FLI in these regions. While these projections are bilateral, in all cases the ipsilateral component is the largest. Therefore, if electrical stimulation (either orthoor antidromic) was the only factor involved in eliciting changes in FLI, one would expect a predominantly ipsilateral distribution of cells with FLI in the NTS and VLM. As we observed symmetrical levels of FLI between the two sides, we have interpreted our results to suggest that any changes due to electrical stimulation of the PBN are overshadowed by the accompanying cardiovascular effects. 

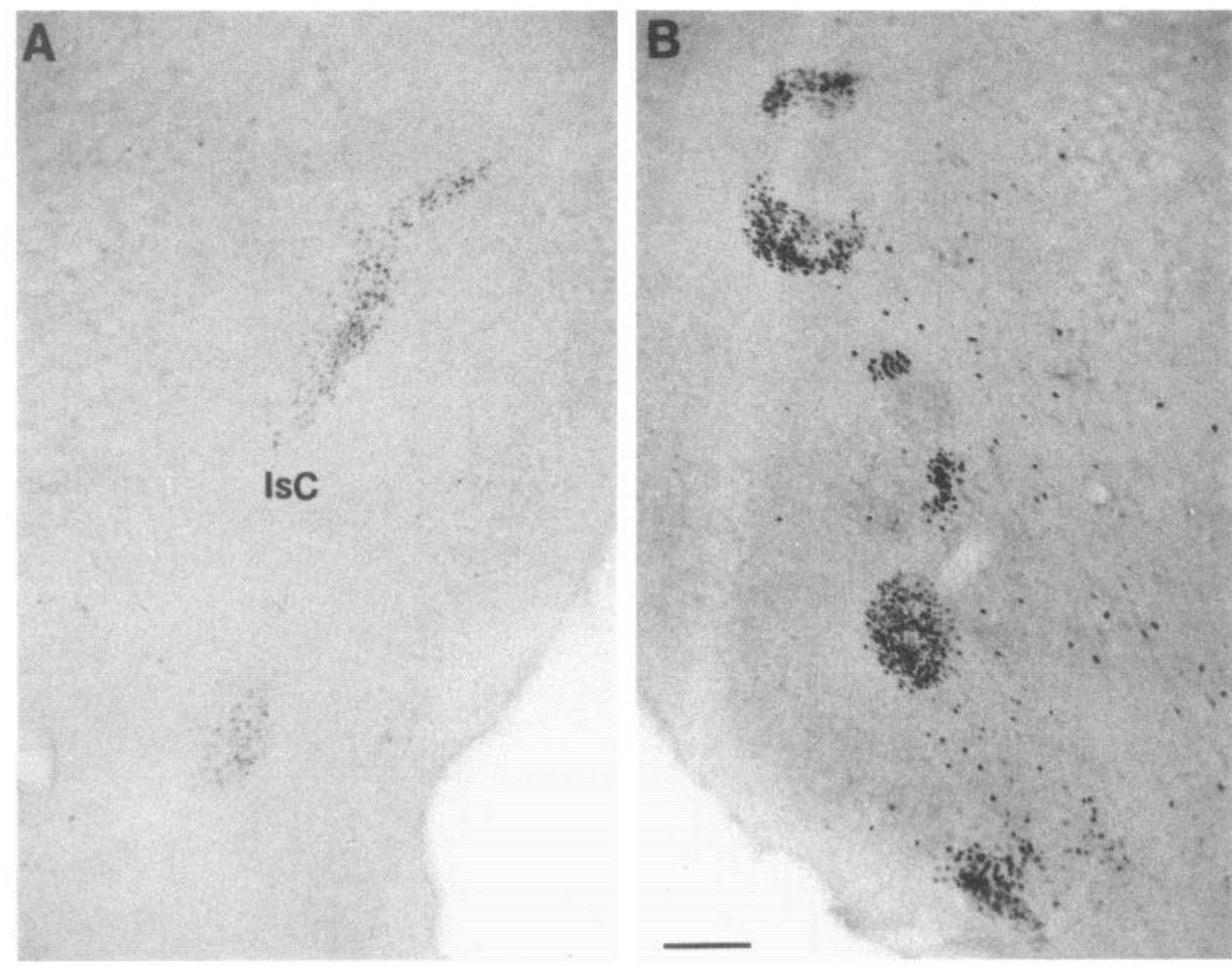

Figure 9. FLI in islands of Calleja (IsC) in urethane-anesthetized rats in which the PBN was stimulated on one side. Immunostaining in the nuclei contralateral to stimulation $(A)$ was similar to that seen in rats anesthetized only. Nuclei ipsilateral to stimulation showed increases in FLI $(B)$. Scale bar, $100 \mu \mathrm{m}$ (for $A$ and $B$ ).

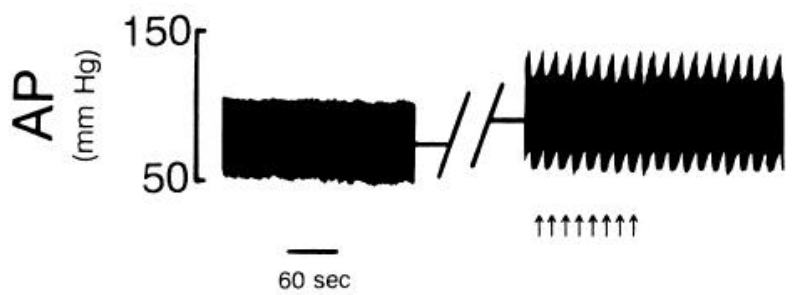

Figure 10. Tracings of arterial pressure $(A P, \mathrm{~mm} \mathrm{Hg})$ in a rat anesthetized with urethane (first segment of trace) and during electrical stimulation of the PBN (second segment of trace). Baseline arterial pressure was elevated during the period of stimulation and pulses of current (arrows) caused additional increases in arterial pressure.

\section{Conclusions}

We have determined the effects of two commonly used anesthetics on Fos expression in the brain. Our results are consistent with previously reported findings that sodium pentobarbital anesthesia leads to a generalized neuronal depression in the brain. On the other hand, urethane anesthesia leads to an increase in FLI in autonomic centers that may be related to the decrease in arterial pressure that has been observed to occur with the use of this anesthetic. Finally, electrical stimulation of the PBN leads to increases in FLI within discrete autonomic sites that are either ipsilateral, suggesting a direct effect of the stimulation, or bilateral, suggesting an indirect effect of arterial pressure increases that accompany PBN stimulation.

\section{References}

Anton F, Herdegen T, Peppel P, Leah JD (1991) c-fos-like immunoreactivity in rat brainstem neurons following noxious chemical stimulation of the nasal mucosa. Neuroscience 41:629-641.

Armstrong JM, Lefevre-Borg F, Scatton B, Cavero I (1982) Urethane inhibits cardiovascular responses mediated by the stimulation of $\alpha_{2}$ adrenoceptors. J Pharmacol Exp Ther 223:524-535.
Baum D, Halter JB, Taborsky GJ, Porte D (1985) Pentobarbital effects on plasma catecholamines: temperature, heart rate, and blood pressure. Am J Physiol 248:E95-E100.

Berkley KJ, Scofield SL (1990) Relays from the spinal cord and solitary nucleus through the parabrachial nucleus to the forebrain in the cat. Brain Res 529:333-338.

Bernard JF, Carroue J, Besson JM (1991) Efferent projections from the external parabrachial area to the forebrain: a Phaseolus vulgaris leucoagglutinin study in the rat. Neurosci Lett 122:257-260.

Block CH, Schwartzbaum JS (1983) Ascending efferent projections of the gustatory parabrachial nucleus in the rabbit. Brain Res 259:1-9.

Block CH, Hoffman G, Kapp BS (1989) Peptide-containing pathways from the parabrachial complex to the central nucleus of the amygdala. Peptides 10:465-471.

Calaresu FR, Yardley CP (1988) Medullary basal sympathetic tone. Annu Rev Physiol 50:511-524.

Calaresu FR, Ciriello J, Caverson MM, Cechetto DF, Krukoff TK (1984) Functional neuroanatomy of central pathways controlling the circulation. In: Hypertension and the brain (Kotchen TA, Guthrie CP, eds), pp 3-21. Mount Kisco, NY: Futura.

Ceccatelli S, Villar MJ, Goldstein M, Hökfelt T (1989) Expression of c-fos immunoreactivity in transmitter-characterized neurons after stress. Proc Natl Acad Sci USA 86:9569-9573.

Cechetto DF, Calaresu FR (1983) Parabrachial units responding to stimulation of buffer nerves and forebrain in the cat. Am J Physiol 245:R811-R819.

Cechetto DF, Saper CB (1987) Evidence for a viscerotopic sensory representation in the cortex and thalamus in the rat. J Comp Neurol 262:27-45.

Curran T (1988) The fos oncogene. In: The oncogene handbook (Reddy EP, ed), pp 307-325. New York: Elsevier.

Doucet JP, Squinto SP, Bazan NG (1990) Fos-jun and the primary genomic response in the nervous system. In: Molecular neurobiology (Bazan NG, ed), pp 27-55. Clifton, NJ: Humana.

Dragunow M, Faull R (1989) The use of c-fos as a metabolic marker in neuronal pathways tracing. J Neurosci Methods 29:261-265.

Dragunow M, Robertson HA, Robertson GS (1988) Amygdala kindling and c-fos protein(s). Exp Neurol 102:261-263.

Feldberg W, Guertzenstein PG (1972) A vasodepressor effect of pentobarbitone sodium. J Physiol (Lond) 224:83-103.

Fulwiler CE, Saper CB (1984) Subnuclear organization of the efferent 
connections of the parabrachial nucleus in the rat. Brain Res Rev 7: 229-259.

Granata AR, Kitai ST (1989) Intracellular study of nucleus parabrachialis and nucleus tractus solitarii interconnections. Brain Res 492: 281-292.

Herbert H, Moga MM, Saper CB (1990) Connections of the parabrachial nucleus with the nucleus of the solitary tract and the medullary reticular formation in the rat. J Comp Neurol 293:540-580.

Herschman HR (1989) Extracellular signals, transcriptional responses and cellular specificity. Trends Biochem Sci 14:455-458.

Holstege $G$ (1988) Anatomical evidence for a strong ventral parabrachial projection to the nucleus raphe magnus and adjacent tegmental field. Brain Res 447:154-158.

Jhamandas JH, Harris KH, Krukoff TL (1991) Projection from parabrachial nucleus towards the hypothalamic supraoptic nucleus: electrophysiological and anatomical observations in the rat. J Comp Neurol 307:1-9.

Jones KJ, Evinger C (1991) Differential neuronal expression of c-fos proto-oncogene following peripheral nerve injury of chemically-induced seizure. J Neurosci Res 28:291-298.

King GW, Knox CK (1982) An electrophysiological study of medullary neurons projecting to nucleus parabrachialis of the cat. Brain Res 236: 27-33.

Krukoff TL, Vu T, Harris KH, Aippersbach S, Jhamandas JH (1992) Neurons in the rat medulla oblongata containing neuropeptide $Y$-, angiotensin II-, or galanin-like immunoreactivity project to the parabrachial nucleus. Neuroscience 47:175-184

Maggi CA, Meli A (1986a) Suitability of urethane anesthesia for physiopharmacological investigations in various systems. Part 2. Cardiovascular system. Experientia 42:292-297.

Maggi CA, Meli A (1986b) Suitability of urethane anesthesia for physiopharmacological investigations in various systems. Part 3. Other systems. Experientia 42:531-536.

Menetrey D, Gannon A, Levine JD, Basbaum AI (1989) Expression of $c$-fos protein in interneurons and projection neurons of the rat spinal cord in response to noxious somatic, articular, and visceral stimulation. J Comp Neurol 285:177-195.

Moga MM, Saper CB, Gray TS (1989) The bed nucleus of the stria terminalis: cytoarchitecture, immunohistochemistry and projection to the parabrachial nucleus in the rat. J Comp Neurol 283:315-332.

Morgan JI, Curran T (1989) Stimulus-transcription coupling in neurons: role of cellular immediate-early genes. Trends Neurosci 12:459_ 462.

Morgan JI, Curran T (1991) Stimulus-transcription coupling in the nervous system: involvement of the inducible proto-oncogenes fos and jun. Annu Rev Neurosci 14:421-451.

Morgan JI, Cohen DR, Hempstead JL, Curran T (1987) Mapping patterns of c-fos expression in the central nervous system after seizure. Science 237:192-197.

Nicholl RA (1979) Differential postsynaptic effects of barbiturates on chemical transmission. In: Neurobiology of chemical transmission (Otsuka M, Hall ZW, eds), pp 267-278. New York: Wiley.

Norgren R, Leonard CM (1973) Ascending central gustatory pathways. J Comp Neurol 150:217-238.

Papas S, Ferguson AV (1990) Electrophysiological characterization of reciprocal connections between the parabrachial nucleus and the area postrema in the rat. Brain Res Bull 24:577-582.

Popovici T, Represa A, Crepel V, Barbin G, Beaudoin M, Ben-Ari Y (1990) Effects of kainic acid-induced seizures and ischemia on c-foslike proteins in rat brain. Brain Res 536:183-194.

Reinert H (1964) Urethane hyperglycaemia and hypothalamic activation. Nature 204:889-891.

Richter JA, Holman JR (1982) Barbiturates: their in vivo effects and potential biochemical mechanisms. Prog Neurobiol 18:275-319.

Ross CA, Ruggiero DA, Reis DJ (1981) Afferent projections to cardiovascular portions of the nucleus of the tractus solitarius in the rat. Brain Res 223:402-408.

Sagar SM, Sharp FR, Curran T (1988) Expression of c-fos protein in brain: metabolic mapping at the cellular level. Science 240:13281331.

Saper CB (1982) Convergence of autonomic and limbic connections in the insular cortex of the rat. J Comp Neurol 210:163-173.

Saper CB, Loewy AD (1980) Efferent connections of the parabrachial nucleus in the rat. Brain Res 197:291-317.

Sapru HN, Krieger AJ (1979) Cardiovascular and respiratory effect of some anesthetics in the decerebrate rat. Eur $\mathrm{J}$ Pharmacol 53:151-158.

Schwaber JS, Sternini C, Brecha NC, Rogers WT, Card JP (1988) Ncurons containing calcitonin gene-related peptide in the parabrachial nucleus project to the central nucleus of the amygdala. J Comp Neurol 270:416-426.

Sheng M, Greenberg ME (1990) The regulation and function of c-fos and other immediate early genes in the nervous system. Neuron 4: $477-485$.

Touzani K, Ferssiwi A, Velley L (1990) Localization of lateral hypothalamic neurons projecting to the medial part of the parabrachial area of the rat. Neurosci Lett 114:17-21.

van der Kooy D, Koda LY (1983) Organization of the projections of a circumventricular organ: the area postrema in the rat. J Comp Neurol 219:328-335.

Ward DG (1988) Stimulation of the parabrachial nuclei with monosodium glutamate increases arterial pressure. Brain Res 462:383-390.

Wild JM, Arends JJA, Zeigler IP (1990) Projections of the parabrachial nucleus in the pigeon (Columba livia). J Comp Neurol 293:499523. 